\title{
Faktor-Faktor yang Mempengaruhi Peningkatan Pendapatan Usaha Mikro (Studi Pada Nasabah BMT As-Salam)
}

\author{
${ }^{1 *}$ Nurul Ichsan, ${ }^{2}$ Husnu Sulukiah Shafriyani \\ ${ }^{1,2}$ Universitas Islam Negeri Syarif Hidayatullah Jakarta, Indonesia \\ *Email korenpondensi: nurul.ichsan@uinjkt.ac.id
}

\begin{abstract}
The purposes of this research are to analyze some factors which affected the increasing income of micro-business and to understand the income difference before and after receive financing from BMT As-Salam. The data analysis method that the writer used is descriptive analysis, Ancova test and a non-parametric test Wilcoxon. The report of this study shows Syariah micro financing, characteristics of profile respondent (education), and characteristics of business respondents (the amount of financing) have an impact towards the increasing income of a micro business. However, characteristic profile respondents (sex, age) and characteristics of the business respondent (the type of business, years of business) have no impact regarding the increasing income of a micro business, and there are a business income differences before and after receiving the financing from As-Salam BMT.
\end{abstract}

Keywords: Jakarta Islamic Index, Rupiah exchange rate, SBI interest rate, Inflation

\begin{abstract}
Abstrak
Penelitian ini bertujuan untuk menganalisis faktor-faktor yang mempengaruhi peningkatan pendapatan usaha mikro dan untuk mengetahui perbedaan pendapatan usaha antara sebelum dan sesudah menerima pembiayaan dari BMT As-Salam. Metode analisis data yang digunakan adalah analisis deskriptif, uji Ancova, dan uji Non Parametrik Wilcoxon. Hasil penelitian menunjukkan pembiayaan mikro syariah, karakteristik profil responden (pendidikan), dan karakteristik usaha responden (besar pembiayaan) berpengaruh terhadap peningkatan pendapatan usaha mikro. Sedangkan, karakteristik profil responden (jenis kelamin, usia) dan karakteristik usaha responden (jenis usaha, lama usaha) tidak berpengaruh terhadap peningkatan pendapatan usaha mikro, dan terdapat perbedaan pendapatan usaha antara sebelum dan sesudah menerima pembiayaan dari BMT As-Salam.
\end{abstract}

Kata kunci: BMT, Peningkatan Pendapatan Usaha, Pembiayaan Mikro Syariah

Saran sitasi: Ichsan, N., \& Shafriyani H.S.. (2019). Faktor-Faktor yang Mempengaruhi Peningkatan Pendapatan Usaha Mikro (Studi Pada Nasabah BMT As-Salam). Jurnal Ilmiah Ekonomi Islam, 5(01), 72-80. doi: http://dx.doi.org/10.29040/jiei.v5i01.464

DOI: http://dx.doi.org/10.29040/jiei.v5i01.464

1. Pendahuluan

Dalam sebuah negara yang sedang berkembang (NSB), banyak sekali permasalahan yang menjadi penghambat bagi perkembangan negara untuk maju menuju tahap selanjutnya.
Salah satu permasalahan yang menjadi prioritas perhatian dari pemerintah adalah kemiskinan (Mariyanti, 2013). Berdasarkan data yang diperoleh dari BPS pada Maret 2017, jumlah penduduk miskin di Indonesia mencapai 27,77 


\section{Jurnal Ilmiah Ekonomi Islam, 5(01), 2019, 74}

juta orang atau 10,64 persen. Menurut Qadir (2001) kemiskinan merupakan ancaman besar umat manusia. Dengan alasan ini, pemerintah selalu mencari jalan keluar untuk menyelamatkan bangsa dari kemiskinan. Salah satu usaha yang dilakukan pemerintah adalah dengan memajukan usaha mikro.

Potensi besar yang dimiliki usaha mikro dalam membangun perekonomian merupakan suatu alat pemerintah dalam menggerakan bidang perekonomian dikarenakan keikutsertaan usaha mikro terhadap PDB nasional berkontribusi besar dan mempunyai potensi yang tinggi dalam menampung tenaga kerja. Hal tersebut dapat dilihat dari banyaknya unit usaha, penyerapan tenaga kerja, serta kontribusinya terhadap Produk Domestik Bruto (PDB) yang mengalami peningkatan pada tahun 2012-2017.

Tabel 1. Perkembangan Data Usaha Mikro Tahun 2012-2017

\begin{tabular}{|c|c|c|c|}
\hline Tahun & $\begin{array}{c}\text { Unit } \\
\text { Usaha }\end{array}$ & $\begin{array}{c}\text { Tenaga } \\
\text { Kerja }\end{array}$ & $\begin{array}{c}\text { PDB atas } \\
\text { Harga } \\
\text { Konstan 2000 }\end{array}$ \\
\hline 2012 & 54.559 .969 & 94.957 .797 & $761.228,8$ \\
\hline 2013 & 55.856 .176 & 99.859 .517 & $790.825,6$ \\
\hline 2014 & 57.189 .393 & 104.624 .466 & $807.804,5$ \\
\hline 2015 & 58.521 .987 & 110.807 .864 & $848.985,0$ \\
\hline 2016 & 60.863 .578 & 103.839 .015 & $2.736 .613,7$ \\
\hline 2017 & 62.106 .900 & 107.232 .992 & $2.856 .607,8$ \\
\hline Sumber: Kementerian & Koperasi dan & Usaha Kecil \\
Menegah, diolah 2018.
\end{tabular}

Sebagian besar usaha mikro yang ada di Indonesia mengalami tantangan pada sektor permodalan. Menurut Hidayati dkk (2014) permasalahan klasik dan mendasar yang dihadapi oleh pelaku usaha mikro kecil menengah ialah permasalahan modal. Hal inilah yang menjadi tantangan bagi usaha mikro untuk tetap mampu mempertahankan keberadaannya dan mampu berkembang dengan keterbatasan dan berbagai kendala yang ada.

Penggerak usaha mikro masih dapat dikatakan belum layak memenuhi syarat-syarat menerima pembiayaan dari lembaga pemberi biaya karena beresiko tinggi dari usaha mikro tersebut yang menjadikan lembaga pemberi pembiayaan sangat teliti menyediakan pinjaman.
Hal ini juga terkait dengan sedikitnya penggerak usaha mikro yang mempunyai jaminan untuk dijadikan agunan sebagai syarat pinjaman.

Baitul Maal wat Tamwil (BMT) merupakan salah satu lembaga keuangan mikro syariah yang dapat mendukung permodalan usaha mikro. Menurut Gina dan Effendi (2014) pembiayaan yang diberikan oleh lembaga informal seperi BMT merupakan alternatif bagi usaha mikro untuk mendapatkan modal dalam mengembangkan usahanya, sehingga dengan adanya tambahan modal pelaku usaha mikro dapat meningkatkan produksi.

\section{a. Rumusan Masalah}

1) Bagaimana pengaruh pembiayaan mikro syariah, karakteristik profil responden (jenis kelamin, usia, pendidikan), karakteristik usaha responden (jenis usaha, lama usaha, besar pembiayaan) terhadap peningkatan pendapatan usaha mikro?

2) Apakah terdapat perbedaan pendapatan usaha antara sebelum dan sesudah menerima pembiayaan dari BMT As-Salam?

\section{b. Tujuan Penelitian}

Berdasarkan rumusan masalah diatas, maka tujuan dari penelitian ini adalah untuk:

1) Menganalisis pengaruh pembiayaan mikro syariah, karakteristik profil responden (jenis kelamin, usia, pendidikan), karakteristik usaha responden (jenis usaha, lama usaha, besar pembiayaan) terhadap peningkatan pendapatan usaha mikro.

2) Menganalisis perbedaan pendapatan usaha antara sebelum dan sesudah menerima pembiayaan dari BMT As-Salam.

\section{Tinjauan Literatur}

\section{a. Baitul Maal wat Tamwil (BMT)}

BMT merupakan lembaga keuangan mikro syariah yang dioperasikan dengan prinsip bagi hasil, bertujuan menumbuh kembangkan bisnis usaha mikro dalam upaya membela kepentingan kaum fakir miskin, ditumbuhkan atas prakarsa dan modal awal dari tokoh-tokoh masyarakat setempat dengan berlandaskan pada sistem ekonomi yang berintikan keadilan (Rahmawati, 2015). 


\section{b. Pembiayaan Mikro Syariah}

Pembiayaan mikro adalah fasilitas pembiayaan yang diberikan untuk kelangsungan dari usaha mikro (Prayogi dan Siregar, 2017). Menurut Undang-Undang No. 21 Tahun 2008 tentang perbankan syariah yang dimaksud dengan pembiayaan adalah penyediaan dana atau tagihan yang dipersamakan dengan itu berupa (Sholihat dkk, 2015): a) Transaksi bagi hasil dalam bentuk mudharabah dan musyarakah; b) Transaksi sewa-menyewa dalam bentuk ijarah atau sewa beli dalam bentuk ijarah muntahiya bittamlik; c) Transaksi jual beli dalam bentuk piutang murabahah, salam, dan istishna'; d) Transaksi pinjam meminjam dalam bentuk piutang qardh; e) Transaksi sewa-menyewa jasa dalam bentuk ijarah untuk transaksi multi jasa.

\section{c. Usaha Mikro}

Menurut Undang-Undang Nomor 20 Tahun 2008 Pasal 1 ayat (1) Usaha Mikro adalah usaha produktif milik orang perorangan dan/atau badan usaha perorangan yang memenuhi kriteria Usaha Mikro sebagaimana diatur dalam UndangUndang ini. Adapun kriteria usaha mikro dapat dilihat pada Pasal 6 ayat (1) disebutkan bahwa:

1) Usaha mikro memiliki kekayaan bersih paling banyak Rp 50.000.000,- (lima puluh juta rupiah) tidak termasuk tanah dan bangunan tempat usaha; atau

2) Memiliki hasil penjualan tahunan paling banyak Rp 300.000.000,- (tiga ratus juta rupiah).

Menurut Siarno (2015) permasalahan yang sering dihadapi oleh usaha mikro meliputi: aspek pemasaran, aspek manajemen, aspek teknis, dan aspek keuangan.

\section{Metode Penelitian}

\section{a. Ruang Lingkup Penelitian}

Penelitian ini dilakukan untuk menganalisis faktor-faktor yang mempengaruhi peningkatan pendapatan usaha mikro. Indikator peningkatan pendapatan usaha mikro dalam penelitian ini adalah keuntungan usaha yang diperoleh nasabah setelah menerima pembiayaan (modal). Penelitian ini dilakukan dengan mengambil studi kasus pada usaha nasabah yang telah
Islam, 5(01), 2019, 75

memperoleh pembiayaan dari BMT As-Salam. Lokasi penelitian ini dilaksanakan di BMT AsSalam Cianjur.

\section{b. Metode Penentuan Sampel}

Populasi dalam penelitian ini adalah seluruh nasabah yang memperoleh pembiayaan dari BMT As-Salam. Penelitian mengambil sampel sebesar 40 responden yang diambil dengan menggunakan $25 \%$ sampel dari jumlah populasi.

\section{c. Metode Pengumpulan Data}

Pengumpulan data dalam penelitian ini menggunakan data primer dan data sekunder. Data primer yang digunakan berupa data hasil kuesioner atau data yang diperoleh langsung yang disebarkan kepada para nasabah pembiayaan BMT As-Salam.

\section{d. Metode Analisis Data}

Metode analisis data yang digunakan dalam penelitian yaitu analisis deskriptif, uji Ancova, dan uji Non Parametrik Wilcoxon. Analisis deskriptif dilakukan untuk mendeskripsikan gambaran umum BMT As-Salam, serta mendeskripsikan karakterisitik profil nasabah yang meliputi jenis kelamin, usia, pendidikan dan karakteristik usaha nasabah yaitu jenis usaha, lama usaha dan besar pembiayaan.

Uji Ancova digunakan untuk mengetahui pengaruh pembiayaan mikro syariah, karakteristik profil responden (jenis kelamin, usia, pendidikan), karakteristik usaha responden (jenis usaha, lama usaha, besar pembiayaan) terhadap peningkatan pendapatan usaha mikro. Kemudian uji Non Parametrik Wilcoxon digunakan untuk mengetahui perbedaan pendapataan usaha antara sebelum dan sesudah menerima pembiayaan dari BMT As-Salam.

\section{e. Operasional Variabel Penelitian}

Variabel bebas (variabel independen) dalam penelitian ini yaitu: pembiayaan mikro syariah, karakteristik profil responden (jenis kelamin, usia, dan pendidikan), karakteristik usaha responden (jenis usaha, lama usaha, dan besar pembiayaan). Sedangkan, variabel terikat (variabel dependen) yang digunakan adalah peningkatan pendapatan usaha mikro, yaitu keuntungan usaha yang diperoleh setelah menerima pembiayaan (modal). 


\section{Hasil dan Pembahasan}

\section{Jurnal Ilmiah Ekonomi Islam, 5(01), 2019, 76}

\section{a. Gambaran Umum BMT As-Salam}

Yang melatar belakangi didirikan BMT AsSalam ini adalah pertama, sebagai upaya menghindarkan masyarakat dari praktek-praktek rentenir yang berada di daerah Cianjur. Kedua, sebagai salah satu bentuk riil dakwah jihad dalam bidang ekonomi. Ketiga, sebagai salah satu alternatif pilihan masyarakat untuk menjadi mitra finansial yang sesuai dengan syariat Islam. Hingga saat ini sudah memiliki Badan Hukum Koperasi Syariah dengan perubahan terakhir No. BH. 523 B/PAD/BH-KDK /IX.7/BID.KOP/2012 Tanggal: 14 September 2012.

Produk dan jasa BMT As-Salam berupa: saham syariah (SAHARA), deposito murabahah, tabungan tassalam, tabungan pelajar (TALAR), dan tabungan hari raya (TAHARA).

\section{b. Hasil Deskriptif Karakteristik Profil Responden}

1) Jenis Kelamin Responden

Tabel 1. Jenis Kelamin Responden

\begin{tabular}{|c|c|c|}
\hline Jenis Kelamin & Jumlah & Persentase (\%) \\
\hline Laki-laki & 11 & 27,5 \\
\hline Perempuan & 29 & 72,5 \\
\hline Total & 40 & 100,0 \\
\hline
\end{tabular}

Sumber: Data Primer yang diolah 2018.

Berdasarkan tabel di atas, menunjukan bahwa sebagian besar responden nasabah dari BMT As-Salam yang diambil sebagai sampel adalah perempuan.

2) Usia Responden

Tabel 2. Usia Reponden

\begin{tabular}{|c|c|c|}
\hline Usia & Jumlah & Persentase (\%) \\
\hline$<20$ tahun & 0 & 0 \\
\hline $20-30$ tahun & 6 & 15,0 \\
\hline $31-50$ tahun & 25 & 62,5 \\
\hline$>50$ tahun & 9 & 22,5 \\
\hline Total & 40 & 100,0 \\
\hline
\end{tabular}

Sumber: Data Primer yang diolah 2018.

Berdasarkan tabel di atas, menunjukan bahwa sebagian besar responden nasabah dari BMT As-Salam yang diambil sebagai sampel berumur $31-50$ tahun.
3) Pendidikan Responden

Tabel 3. Pendidikan Responden

\begin{tabular}{|c|c|c|}
\hline Pendidikan & Jumlah & Persentase (\%) \\
\hline SD & 30 & 75,0 \\
\hline SMP & 6 & 15,0 \\
\hline SMA & 4 & 10,0 \\
\hline Perguruan Tinggi & 0 & 0 \\
\hline Total & 40 & 100,0 \\
\hline
\end{tabular}

Sumber: Data Primer yang diolah 2018.

Berdasarkan tabel di atas, menunjukan bahwa sebagian besar responden nasabah dari BMT As-Salam yang diambil sebagai sampel berpendidikan SD.

\section{c. Hasil Deskriptif Karakteristik Usaha Responden}

1) Jenis Usaha Responden

Tabel 4. Jenis Usaha Responden

\begin{tabular}{|c|c|c|}
\hline Jenis Usaha & Jumlah & Persentase (\%) \\
\hline Dagang & 30 & 75,0 \\
\hline Manufaktur & 9 & 22,5 \\
\hline Jasa & 1 & 2,5 \\
\hline Total & 40 & 100,0 \\
\hline
\end{tabular}

Sumber: Data Primer yang diolah 2018.

Berdasarkan tabel di atas, menunjukan bahwa sebagian besar responden nasabah dari BMT As-Salam yang diambil sebagai sampel yaitu yang menjalankan jenis usaha dagang.

2) Lama Usaha Responden

Tabel 5. Lama Usaha Responden

\begin{tabular}{|c|c|c|}
\hline Lama Usaha & Jumlah & Persentase (\%) \\
\hline$<1$ tahun & 0 & 0 \\
\hline $1-2$ tahun & 12 & 30,0 \\
\hline $3-5$ tahun & 19 & 47,5 \\
\hline$>5$ tahun & 9 & 22,5 \\
\hline Total & 40 & 100,0 \\
\hline
\end{tabular}

Sumber: Data Primer yang diolah 2018.

Berdasarkan tabel di atas, menunjukan bahwa sebagian besar responden nasabah dari BMT As-Salam yang diambil sebagai sampel yaitu yang sudah menjalankan usaha selama 3 5 tahun.

3) Besar Pembiayaan Responden

Tabel 6. Besar Pembiayaan Responden

\begin{tabular}{|c|c|c|}
\hline Besar Pembiayaan & Jumlah & Persentase (\%) \\
\hline$<\mathrm{Rp} 1.000 .000$ & 11 & 27,5 \\
\hline $\begin{array}{c}\mathrm{Rp} 1.000 .000-\mathrm{Rp} \\
2.000 .000\end{array}$ & 18 & 45,0 \\
\hline $\begin{array}{c}\mathrm{Rp} 2.000 .001-\mathrm{Rp} \\
3.000 .000\end{array}$ & 9 & 22,5 \\
\hline$>\mathrm{Rp} 3.000 .000$ & 2 & 5,0 \\
\hline Total & 40 & 100,0 \\
\hline
\end{tabular}

Sumber: Data Primer yang diolah 2018. 
Berdasarkan tabel di atas, menunjukan bahwa menunjukan bahwa sebagian besar responden nasabah dari BMT As-Salam yang diambil sebagai sampel yaitu menerima pembiayaan Rp 1.000.000 - Rp 2.000.000.

\section{d. Hasil Uji Ancova}

Sebelum dilakukan uji Ancova, maka dilakukan uji kesamaan varians (homogenitas) dengan Levene Test. Signifikansi harus lebih dari 0,05 agar varians yang sama dapat terpenuhi. Hasil uji homogenitas varians pada penelitian ini dapat dilihat pada tabel berikut:

\section{Tabel 7. Hasil Uji Homogenitas}

Levene's Test of Equality of Error Variances ${ }^{a}$ Dependent Variable:

Pendapatan_Sesudah_Pembiayaan

\begin{tabular}{|c|r|r|r|}
\hline F & df1 & df2 & Sig. \\
\hline 1,276 & 30 & & 9 \\
\hline
\end{tabular}

Tests the null hypothesis that the error variance of the dependent variable is equal across groups.

a. Design: Intercept + Jenis_Kelamin + Usia + Pendidikan + Jenis_Usaha + Lama_Usaha + Besar_Pembiayaan + Modal_Sesudah_Pembiayaan Sumber: Data Primer yang diolah 2018.

Berdasarkan tabel Levene Test diatas diketahui bahwa, nilai Sig 0,367 lebih besar daripada taraf signifikansi $(\alpha)=0,05$. Maka dapat disimpulkan bahwa varian antar kelompok adalah sama, sehingga Uji Ancova dapat dilakukan.

Tabel 8. Hasil Uji Ancova

Tests of Between-Subjects Effects

Dependent Variable: Pendapatan_Sesudah_Pembiayaan

\begin{tabular}{|l|r|r|r|r|r|}
\hline Source & \multicolumn{1}{|c|}{ Type III Sum of Squares } & \multicolumn{1}{|c|}{ Df } & \multicolumn{1}{c|}{ Mean Square } & \multicolumn{1}{c|}{ F } & Sig. \\
\hline Corrected Model & 26645707768908,996 & 13 & 2049669828377,615 & 25,078 &, 000 \\
Intercept & 2039856257,197 & 1 & 2039856257,197 &, 025 &, 876 \\
Jenis_Kelamin & 39473566438,294 & 1 & 39473566438,294 &, 483 &, 493 \\
Usia & 163207195479,512 & 2 & 81603597739,756 &, 998 &, 382 \\
Pendidikan & 1147743865353,835 & 2 & 573871932676,918 & 7,021 &, 004 \\
Jenis_Usaha & 217766896028,293 & 2 & 108883448014,146 & 1,332 &, 281 \\
Lama_Usaha & 62209410419,803 & 2 & 31104705209,901 &, 381 &, 687 \\
Besar_Pembiayaan & 1054551486578,149 & 3 & 351517162192,716 & 4,301 &, 014 \\
Modal_Sesudah_Pembi & 1356276687944,991 & 1 & 1356276687944,991 & 16,594 &, 000 \\
ayaan & 2125065006091,004 & 26 & 81733269465,039 & & \\
Error & 84686469000000,000 & 40 & & & \\
Total & 28770772775000,000 & 39 & & & \\
Corrected Total & & & & \\
\hline
\end{tabular}

a. R Squared $=, 926$ (Adjusted R Squared $=, 889$ )

Sumber: Data Primer yag diolah 2018.

Berdasarkan hasil diatas, dengan taraf signifkansi 5\% dapat disimpulkan bahwa variabel yang memiliki pengaruh terhadap peningkatan pendapatan usaha mikro adalah variabel pembiayaan mikro syariah (modal sesudah pembiayaan) $0,000<0,05$, variabel karakteristik profil reponden (pendidikan) 0,004 $<0,05$, dan variabel karakteristik usaha responden (besar pembiayaan) 0,014 $<0,05$. Sedangkan, variabel karakteristik profil reponden (jenis kelamin, usia) dan variabel karakteristik usaha responden (jenis usaha, lama usaha) tidak berpengaruh terhadap peningkatan pendapatan usaha mikro atau signifikansi $>0,05$.

\section{e. Hasil Uji Non Parametrik Wilcoxon}

Hasil uji Non Parametrik Wilcoxon pada penelitian ini adalah sebagai berikut:

Tabel 9. Hasil Uji Wilcoxon Test Statistics

Test Statistics ${ }^{\mathrm{a}}$

\begin{tabular}{|l|r|}
\hline & $\begin{array}{c}\text { Pendapatan_Sesudah_ } \\
\text { Pembiayaan - } \\
\text { Pendapatan_Sebelum_ } \\
\text { Pembiayaan }\end{array}$ \\
\hline Z & $-5,511^{\mathrm{b}}$ \\
Asymp. Sig. (2-tailed) &, 000 \\
\hline
\end{tabular}

a. Wilcoxon Signed Ranks Test

b. Based on negative ranks.

Sumber: Data Primer yang diolah 2018. 


\section{Jurnal Ilmiah Ekonomi Islam, 5(01), 2019, 78}

Berdasarkan hasil ouput Test Statistics diatas, nilai $\mathrm{Z}$ yang didapat sebesar $-5,511$ dengan $\mathrm{p}$ value (Asymp. Sig. 2-tailed) sebesar $0.000<$ 0,05 . Hal ini menunjukkan bahwa terdapat perbedaan antara pendapatan usaha sebelum menerima pembiayaan dengan pendapatan sesudah menerima pembiayaan dari BMT AsSalam. Perubahan kenaikan pendapatan ini menunjukkan pada perubahan positif.

Tabel 10. Hasil Uji Wilcoxon Ranks

Ranks

\begin{tabular}{|ll|l|l|l|}
\hline & N & Mean Rank & Sum of Ranks \\
\hline Pendapatan_Sesudah_Pembiayaan - Negative Ranks & $0^{\mathrm{a}}$ &, 00 &, 00 \\
Pendapatan_Sebelum_Pembiayaan Positive Ranks & $40^{\mathrm{b}}$ & 20,50 & 820,00 \\
& $0^{\mathrm{c}}$ & & \\
& Ties & 40 & & \\
\hline
\end{tabular}

a. Pendapatan_Sesudah_Pembiayaan < Pendapatan_Sebelum_Pembiayaan

b. Pendapatan_Sesudah_Pembiayaan $>$ Pendapatan_Sebelum_Pembiayaan

c. Pendapatan_Sesudah_Pembiayaan = Pendapatan_Sebelum_Pembiayaan

\section{Sumber: Data Primer yang diolah 2018.}

Tabel Ranks diatas menggambarkan peningkatan pendapatan usaha sebelum dan sesudah menerima pembiayaan dengan perolehan nilai positive ranks seluruh nasabah yaitu 40 . Hal ini menunjukkan bahwa 40 nasabah mengalami peningkatan pendapatan usaha setelah menerima pembiayaan dari BMT As-Salam. Data nilai minimum keuntungan awal sebesar 75.000 dan

maximum sebesar 1.250 .000 , sedangkan nilai minimum keuntungan akhir sebesar 240.000 dan maximum sebesar 4.500.000. nilai mean atau rata-rata nilai keuntungan akhir sebesar 1.182.325 dimana lebih besar dari pada nilai mean keuntungan awal yaitu sebesar 395.850. Untuk lebih jelasnya dapat dilihat pada Tabel 11. berkut:

Tabel 11. Hasil Uji Wilcoxon Descriptive Statistics

Descriptive Statistics

\begin{tabular}{|l|r|r|r|r|r|}
\hline & \multicolumn{1}{|c|}{ N } & \multicolumn{1}{c|}{ Mean } & Std. Deviation & Minimum & Maximum \\
\hline Pendapatan_Sebelum_Pembiayaan & 40 & 395850,00 & 287116,393 & 75000 & 1250000 \\
Pendapatan_Sesudah_Pembiayaan & 40 & 1182325,00 & 858901,695 & 240000 & 4500000 \\
\hline
\end{tabular}

Sumber: Data Primer yang diolah 2018.

\section{Kesimpulan}

Berdasarkan hasil penelitian dan pembahasan yang telah dilakukan, maka dapat diambil kesimpulan bahwa:

a. Pembiayaan mikro syariah, karakteristik profil responden (pendidikan), dan karakteristik usaha responden (besar pembiayaan) berpengaruh terhadap peningkatan pendapatan usaha mikro atau nilai signifikansi $<0,05$. Sedangkan, karakteristik profil reponden (jenis kelamin, usia) dan karakteristik usaha responden (jenis usaha, lama usaha) tidak berpengaruh terhadap peningkatan pendapatan usaha mikro atau signifikansi $>0,05$.

b. Terdapat perbedaan pendapatan usaha antara sebelum dan sesudah menerima pembiayaan dari BMT As-Salam. Berdasarkan hasil uji Non Parametrik Wilcoxon, diperoleh nilai Z sebesar -5,511 dengan $\mathrm{p}$ value (Asymp. Sig. 2 -tailed) sebesar $0.000<0,05$. Sehingga dapat disimpulkan bahwa terdapat perbedaan antara pendapatan usaha sebelum dengan pendapatan usaha sesudah menerima pembiayaan dari BMT As-Salam.

\section{Daftar Pustaka}

Anggraeni, Lukytawati. dkk. 2013. Akses UMKM Terhadap Pembiayaan Mikro Syariah dan Dampaknya Terhadap Perkembangan Usaha : Kasus BMT Tadbiirul Ummah, Kabupaten Bogor. Jurnal al-Muzara'ah, Vol. I, No. 1, 2013. 
Arikunto, Suharsimi. 2008. Prosedur Penelitian: Suatu Pendekatan Praktik. Jakarta: Rineka Cipta.

Damayanti, Nurul Farida dan Sri Herianingrum. 2014. Pengaruh Pembiayaan Dana Baitul Maal Wat Tamwil (BMT) Teladan Terhadap Kinerja Usaha Mikro di Pasar Semolowaru Surabaya. JESTT Vol. 1 No. 3 Maret 2014.

Gina, Widya dan Jaenal Effendi. 2014. Program Pembiayaan Lembaga Keuangan Mikro Syariah (LKMS) dalam Peningkatan Kesejahteraan Pelaku Usaha Mikro (Studi Kasus BMT Baitul Karim Bekasi). Jurnal AlMuzara'ah, Vol. 3, No. 1.

Hidayati, Nadiah. dkk. 2014. Faktor-faktor yang Memengaruhi Realisasi Pembiayaan Mikro Syariah dan Dampaknya Terhadap Omzet Usaha Nasabah: Studi Kasus KJKS BMT UGT Sidogiri Cabang Koja Jakarta. Jurnal Al-Muzara'ah, Vol. 2, No. 1.

Huda, Nurul. dkk. 2016. Baitul Mal Wa Tamwil. Jakarta: Amzah.

Iskandar, Syamsu. 2013. Bank dan Lembaga Keuangan Lainnya. Jakarta: In Media.

Ismanto, Kuat. 2015. Pengelolaan Baitul Maal pada Baitul Maal Wa Tamwil (BMT) di Kota Pekalongan. Jurnal Penelitian, Vol. 12, No. 1, Mei 2015. Hlm. 24-38.

Kadim, Dorce Novita. dkk. 2017. Pengaruh Jumlah Produksi, Pengalaman Usaha dan Jenis Kelamin Terhadap Pendapatan Usaha Tukang Jahit di Presiden Shopping Center Kecamatan Wenang Kota Manado. Jurnal Berkala Ilmiah Efisiensi, Volume 17 No. 02 Tahun 2017.

Kadir. 2015. Statistika Terapan: Konsep, Contoh dan Analisis Data dengan Program SPSS/Lisrel dalam Penelitian. Jakarta: Rajawali Pers.

Kasim, M. Arif Budiman dan Izzuddin Edi Siswanto. Analisis Efektivitas Pendayagunaan Zakat Produktif Pada Program Pemberdayaan Masyarakat di Wilayah Sukabumi (Studi Kasus: Kampoeng Ternak Dompet Dhuafa). Jurnal STEI SEBI, 2016.
Mariyanti, Tatik. 2013. Pengaruh Zakat dan Pembiayaan BMT dalam Penurunan Kemiskinan. Jurnal Ekonomi Islam Republika, Kamis 22 Agustus 2013.

Mbogo, Michael Kuria dan Willy Muturi. 2014. The Effect of MFI Credit on Revenue of SMEs, a Survey of Small Medium Enterprises in Nakuru Town. International Journal of Science and Research (IJSR), Volume 3 Issue 6, June 2014.

Mufarrohah. dkk. 2015. Analisis Faktor - Faktor yang Memengaruhi Peningkatan Pendapatan Pada Usaha Mikro (Pedagang Kaki Lima di Alun-Alun Besuki Kabupaten Situbondo). Artikel Ilmiah Mahasiswa 2015.

Murwanti, Sri dan Muhammad Sholahuddin. 2013. Peran Keuangan Lembaga Mikro Syariah Untuk Usaha Mikro di Wonogiri. Proceeding Seminar Nasional dan Call For Papers Sancall 2013.

Nainggolan, Romauli. 2016. Gender, Tingkat Pendidikan dan Lama Usaha Sebagai Determinan Penghasilan UMKM Kota Surabaya. KINERJA, Volume 20, No.1, Th. 2016: Hal. 1-12.

Nurfilaeli, Dhika. 2014. Persepsi Nasabah Mengenai Pengaruh Pembiayaan Syariah Terhadap Peningkatan Pendapatan Usaha Kecil Menengah Pada BMT Mentari Bumi Kemangkon Purbalingga.KOMPARTEMEN, Vol. XII No.2, September 2014.

Nurhasanah, Neneng. 2013. Pengawasan Islam dalam Operasional Lembaga Keuangan Syariah. MIMBAR, Vol. 29, No. 1 (Juni, 2013): $11-18$.

Prayogi, Muhammad Andi dan Lukman Hakim Siregar. 2017. Pengaruh Pembiayaan Mikro Syariah Terhadap Tingkat Perkembangan Usaha Mikro Kecil Menengah (UMKM). Jurnal Ekonomi dan Studi Pembangunan, Vol. 17 No. 2, 2017.

Qadir, Abdurrachman. 2001. Zakat (Dalam Dimensi Mahdah dan Sosial). Jakarta: Raja Grafindo Persada, 2001.

Quro'i, Moh. Didanul. 2015. Pengaruh Pembiayaan dan Jenis Usaha Terhadap Peningkatan Pendapatan Nasabah Koperasi Baytul Mal Wat Tamwil (BMT) Nurul Jannah Petrokimia Gresik. Skripsi. Surabaya: Universitas Islam Negeri Sunan Ampel. 
Rahayu, Tri Andina. 2016. Analisis FaktorFaktor yang Memengaruhi Kelancaran Pengembalian Pembiayaan Murabahah pada Usaha Mikro, Kecil, dan Menengah (UMKM) di BMT Taruna Sejahtera. Jurnal Muqtasid, Volume 7 Nomor 1, Juni 2016.

Rahmawati, Yuke. 2013. Lembaga Keuangan Mikro Syariah. Jakarta: UIN Jakarta Press.

Sa'diyah, Mahmudatus. 2014. Pengembangan Produk-Produk Lembaga Keuangan Mikro Syariah. EQUILIBRIUM, Volume 2, No. 1, Juni 2014.

Sarwono, Jonathan. 2014. Riset Skripsi dan Tesis dengan SPSS 22. Jakarta: PT Elex Media Komputindo.

Septiana, Risya Maulida. 2013. Analisis Dampak Pembiayaan Mikro Syariah Terhadap Perkembangan Keuntungan UMKM di Kabupaten Bogor. Skripsi. Bogor : Institut Pertanian Bogor.

Sholihat, Siskawati. dkk. 2015. Analisis Efektivitas Pembiayaan Lembaga Keuangan Mikro Syariah Terhadap Perkembangan Usaha Nasabah di Sektor Rill (Usaha Mikro, Kecil dan Menegah). Al-Infaq: Jurnal Ekonomi Islam, Vol. 6 No. 1, Maret 2015.

Siarno, Si Islam. 2015. Analisis Perkembangan Usaha Mikro dan Kecil Setelah Memperoleh Pembiayaan dari Baitul Mal Wat Tamwil di Kota Surakarta Tahun 2015. Tesis. Surakarta: Institut Agama Islam Negeri Surakarta.

Soemitra, Andri. 2009. Bank dan Lembaga Keuangan Syariah, Jakarta: Kencana.

Sofwatama, Habibi. dkk. 2017. Keberhasilan Kinerja Usaha Lembaga Keuangan Mikro Syariah Baitul Maal Wat Tamwil L-Risma (LKMS BMT L-RISMA) di Provinsi Lampung. JIIA, Volume 5 No. 1 Februari 2017.
Sugiyono. 2009. Metode Penelitian Kuantitatif, Kualitatif dan $R \& D$. Bandung: Alfabeta.

Sujarweni, V. Wiratna dan Poly Endrayanto. 2012. Statistika untuk Penelitian. Yogyakarta: Graha Ilmu.

Suliyono, Joko. 2010. 6 Hari Jago SPSS 17. Yogyakarta: Cakrawala.

Tambunan, Tulus T.H. 2009. UMKM di Indonesia. Bogor: Ghalia Indonesia.

Tanty, Heruna. dkk. 2013. Metode Nonparametrik untuk Analisis Hubungan Perilaku dan Pengetahuan Masyarakat Tentang Kode Plastik. Jurnal Mat Stat, Vol. 13 No. 2 Juli 2013: 97-104.

Tunas, Aldesta Nurika Perwitasari. dkk. 2018. Analisis Pengaruh Pembiayaan Syariah Terhadap Perkembangan Usaha Mikro Kecil Menengah di Kota Depok. Jurnal AlMuzara'ah, Vol. 2, No. 1.

Undang-Udang Republik Indonesia No. 20 Tahun 2008

Undang-Undang Perbankan No. 21 Tahun 2008

Wahyono, Budi. 2017. Analisis Faktor-Faktor yang Mempengaruhi Pendapatan Pedagang di Pasar Bantul Kabupaten Bantul. Jurnal Pendidikan dan Ekonomi, Volume 6, Nomor 4, Tahun 2017.

Yusuf, Ayus Ahmad dan Abdul Aziz. 2009. Manajemen Operasional Bank Syariah. Cirebon: STAIN Press, hal. 68.

http://www.depkop.go.id

www.bps.go.id

www.assalamcianjur.com

Azzam, H.T., (2002). There's considerable rationale to invest in Arab stock markets, Middle East Executive Reports 25, 6-10.

Erdem, C., Arslan, C. K., \& Sema Erdem, M. (2005). Effects of macroeconomic variables on Istanbul stock exchange indexes. Applied Financial Economics, 15(14), 987-994. 